\title{
Modified Malmquist Productivity Index Based on Present Time Value of Money
}

\author{
Farhad Hosseinzadeh Lotfi, ${ }^{1}$ Golamreza Jahanshahloo, ${ }^{1}$ \\ Mohsen Vaez-Ghasemi, ${ }^{1}$ and Zohreh Moghaddas ${ }^{2}$ \\ ${ }^{1}$ Department of Mathematics, Islamic Azad University, Science and Research Branch, P.O. Box 14155/4933, Tehran, Iran \\ ${ }^{2}$ Department of Electrical, Computer and Biomedical Engineering, Islamic Azad University, Qazvin Branch, \\ P.O. Box 34185/1416, Qazvin, Iran
}

Correspondence should be addressed to Farhad Hosseinzadeh Lotfi; farhad@hosseinzadeh.ir

Received 9 September 2012; Revised 11 December 2012; Accepted 30 December 2012

Academic Editor: Mohammad Khodabakhshi

Copyright (C) 2013 Farhad Hosseinzadeh Lotfi et al. This is an open access article distributed under the Creative Commons Attribution License, which permits unrestricted use, distribution, and reproduction in any medium, provided the original work is properly cited.

\begin{abstract}
Data envelopment analysis (DEA) models can calculate the Malmquist Productivity Index (MPI). Classic Malmquist Productivity Index shows regress and progress of a DMU in different periods with efficiency and technology variations without considering the present value of money. This issue is of major importance since while a currency of in previous year is not equal to that of now this would yield bias results which can affect the correct interpretation. The index developed here is defined in terms of Modified Malmquist Productivity Index model, which can calculate progress and regress by using the factor of present time value of money. The incorporation of present time value of money is also calculated within the framework of data envelopment analysis. This factor is fundamental and should be considered in DEA Malmquist Productivity Index. Moreover, here, differences between presented models are compared to those of previous ones indeed, biased results will be shown in the case study in banks, and problem and solution have been investigated in the literature.
\end{abstract}

\section{Introduction}

Data envelopment analysis is mathematical programming technique for obtaining relative efficiency of a set of decision making units (DMUs). Nowadays DEA is widely used in various fields. Utilizing data envelopment analysis (DEA) methodology it is also possible to estimate the Malmquist Productivity Index. As one of the major sources of economic development is productivity growth thus having a comprehensive interpretation of those factors affects productivity is very influential and leading.

Malmquist [1], in 1953, published a quantity index for use in consumption analysis. In this index input distance functions are used to make comparison among two or more consumption bundles. Later in 1982, in production analysis Caves et al. [2], introduced Malmquist Productivity Index on basis of what malmquist has proposed. Nowadays applications which use the Malmquist Productivity Index have become widespread in the literature. In recent years, among researchers who are studying firm performance, the measurement and analysis of productivity change have enjoyed a great deal of attention.

As measuring productivity change gains an important attention in the literature Färe et al. [3] in a paper completely discussed productivity growth, technical progress, and efficiency change. They applied these factors in evaluating industrialized countries. Maniadakis and Thanassoulis [4] developed a productivity index that is an extension of the work on malmquist indexes. They evolved a productivity index which is applicable when input prices are known and producers are cost minimisers. In doing so, they developed a productivity index that accounts not only for technical efficiency and technological variations but also for allocative efficiency and for the effects of input price variations. GrifellTatjé and Lovell [5] provided a paper in order to adopt a different approach to the use of DEA with panel data and 
create a malmquist index of productivity change and provide a new decomposition for it. Grifell-Tatjé et al. [6] provided a new Malmquist Productivity Index called a quasi-Malmquist productivity index which incorporates all slacks on the selected side and replaces conventional radial efficiency measures with the new nonradial efficiency ones. Also, Chen [7], on bases of the fact that DEA-based Malmquist Productivity Index measures the technical and productivity changes over time, has extended the Malmquist Productivity Index into a nonradial index where the decision maker's preference over performance improvement can also be incorporated. The advantage of this index is that by the nonzero slacks it eliminates possible inefficiency.

Since malmquist indexes of productivity are generally estimated using index number techniques or nonparametric frontier approaches Fuentes et al. [8] aimed to estimate malmquist indexes in a similar way using parametric-deterministic or parametric-stochastic frontier approaches. They adopted an output distance function and showed that using the estimated parameters, several radial distance functions can be calculated and moreover combined for estimating and decomposing the productivity indexes. Orea [9] in his paper provided a parametric decomposition of a generalized Malmquist Productivity Index which considers scale economies. As he said in his research the contribution of scale economies to productivity change is evaluated without recourse to scale efficiency measures, which are neither bounded for globally increasing, decreasing, or constant returns to scale technologies nor for ray-homogeneous technologies. Lin et al. [10] in their article considered 117 branches of a certain bank in Taiwan and introduced data envelopment analysis to assess the operating performances of business units of this bank. Their work, in determining operation strategies, provides the reference for a bank's managers. In their investigation Wang and Lin [11] established an analytical hierarchy framework for helping banks in order to choose merger strategies. Also, The consistent fuzzy preference relation is used for improving effectiveness and decision-making consistency. The obtained analytical results shed light on the issue that, in strategy selection, risk management and financial composition of banks are the main considerations. Wu et al. [12] for banking performance evaluation proposed a fuzzy multiple criteria decision-making (FMCDM) approach. Also, the three MCDM analytical tools of SAW, TOPSIS, and VIKOR were respectively adopted to rank the banking performance and improve the gaps with three banks as an empirical example. $\mathrm{Ng}$ et al. [13] indicated that in the banking industry, it is desirable to identify potential bank failure or high-risk banks. Thus, in their paper they have proposed a fuzzy CMAC (cerebellar model articulation controller) model based on compositional rule of inference, called FCMAC-CRI(S), as an innovative way for tackling the problem using localized learning.

Here the aim is to become more precise in calculating Malmquist Productivity Index since in this subject inaccurate inputs would lead to biased results of efficiency. Considering the Malmquist Productivity Index which is used to compute the progress and regress of entities in successive periods we emphasize that it is of major significance to pay concentration while the Malmquist Productivity Index is being calculated for DMUs which have similar performances in time $t$ and time $t+1$. It would be definitely not fair enough to merely consider efficiency variations and technological variations. The fact is that a specific value of money in time $t$ is not equal to that value in time $t+1$, that is, $(10 \$)_{t} \neq(10 \$)_{t+1}$. Thus if technological variations and efficiency variations in time $t$ and time $t+1$ have the same performances, then, the interest rate needs to be considered in time $t+1$. The index developed here is defined in terms of Modified Malmquist Productivity Index model (MMPI), which can calculate progress and regress by using the factor of present time value of money. The incorporation of present time value of money is also calculated within the framework of data envelopment analysis.

The current paper proceeds as follows. In the next section, Malmquist Productivity Index will be briefly reviewed. Then, in Section 3, the proposed method, Modified Malmquist Productivity Index, which is based on the present time value of money, will be discussed. An illustrative example is documented in Section 4 in which main findings are highlighted, and Section 5 concludes the paper with conclusions and recommendation.

\section{Malmquist Productivity Index}

Utilizing DEA methodology it is possible to estimate the Malmquist Productivity Index. As is, DEA models are linear programming (LP) models with which the production frontier can be estimated. Those DMUs located onto this frontier are called efficient and others referred to as inefficient. The degree of efficiency for each DMUs can be obtained on the basis of the Euclidean distance of their input-output ratio from the estimated frontier. Since efficient DMUs construct production frontier thus it can obviously change over time. What Malmquist DEA approach does is to calculate the efficiency measure for one year relative to that of the prior year, while the frontier may change from time to time (time $t$ and time $t+1)$. Thus it can be said that the frontier function has shifted from frontier $t$ to frontier $t+1$.

Let $\mathrm{DMU}_{l}$ denote a unit from a total $n$ units that relative efficiency is being evaluated. Define $x_{l} \in R_{+}^{m}$ and $y_{l} \in R_{+}^{S}$ as semipositive input and output vectors of $\mathrm{DMU}_{l}$. The most general way of characterization of production technology is production possibility set $T$, which is defined with a set of semipositive $(x, y)$ as

$$
T=\left\{(x, y) \mid x \geq \sum_{j=1}^{n} \lambda_{j} x_{j}, y \leq \sum_{j=1}^{n} \lambda_{j} y_{j}, \lambda_{j} \geq 0, j=1, \ldots, n\right\} .
$$

As existed in the literature Malmquist Productivity Index can be calculated via several functions, such as distance function:

$$
D\left(X_{l}, Y_{l}\right)=\operatorname{Min}\left\{\theta:\left(\theta X_{l}, Y_{l}\right) \in T\right\} .
$$


The resultant distance function can be computed by solving linear programming problems. Consider an inputoriented CCR model as follows:

$$
\begin{aligned}
& D^{f}\left(x_{l}^{k}, y_{l}^{k}\right)=\min \theta \\
& \text { s.t. } \quad \sum_{j=1}^{n} \lambda_{j} x_{i j}^{f} \leq \theta x_{i l}^{k}, \quad i=1, \ldots, m, \\
& \\
& \qquad \sum_{j=1}^{n} \lambda_{j} y_{r j}^{f} \geq y_{r l}^{k}, \quad r=1, \ldots, s, \\
& \lambda_{j} \geq 0, \quad j=1, \ldots, n,
\end{aligned}
$$

in which $l$ is the unit under assessment and each of $k$ and $f$ varies between time $t$ and time $t+1$. As an instance for assessing $\mathrm{DMU}_{l}$ consider $k=t$ and $f=t+1, D^{t+1}\left(x_{l}^{t}, y_{l}^{t}\right)$; this means that $\mathrm{DMU}_{l}$ is considered in time $t$ while technology is considered in time $t+1$. Considering this notification, four LP problems can be defined.

In regards of this subject, Caves et al. [2] have introduced the Malmquist Productivity Index as follows in which the results obtained from the mentioned models are being used:

$$
\begin{aligned}
& M\left(x_{l}^{t+1}, y_{l}^{t+1}, x_{l}^{t}, y_{l}^{t}\right) \\
& \quad=\left(\frac{D^{t}\left(x_{l}^{t+1}, y_{l}^{t+1}\right) D^{t+1}\left(x_{l}^{t+1}, y_{l}^{t+1}\right)}{D^{t}\left(x_{l}^{t}, y_{l}^{t}\right) D^{t+1}\left(x_{l}^{t}, y_{l}^{t}\right)}\right)^{1 / 2},
\end{aligned}
$$

in which $x_{l}^{t}$ and $y_{l}^{t}$ are the input and output vectors for unit $l$, used in period $t$. Also, $x_{l}^{t+1}$ and $y_{l}^{t+1}$ are the input and output vectors for unit $l$, used in period $t+1$. This index measures the productivity of unit $l$ at the production $\left(x_{l}^{t+l}, y_{l}^{t+l}\right)$ relative to $\left(x_{l}^{t}, y_{l}^{t}\right)$.

The previously equation can be further decomposed into two components mentioned: one for measuring the change in technical efficiency and the other for measuring the technical change which means the technology frontier shift between the two time periods, $t$ and $t+l$ :

$$
\begin{aligned}
& M\left(x_{l}^{t+1}, y_{l}^{t+1}, x_{l}^{t}, y_{l}^{t}\right) \\
& \quad=\frac{D^{t+1}\left(x_{l}^{t+1}, y_{l}^{t+1}\right)}{D^{t}\left(x_{l}^{t}, y_{l}^{t}\right)}\left[\frac{D^{t}\left(x_{l}^{t+1}, y_{l}^{t+1}\right) D^{t}\left(x_{l}^{t}, y_{l}^{t}\right)}{D^{t+1}\left(x_{l}^{t+1}, y_{l}^{t+1}\right) D^{t+1}\left(x_{l}^{t}, y_{l}^{t}\right)}\right]^{1 / 2} .
\end{aligned}
$$

The interpretation of this equation is that $M\left(x_{l}^{t+1}, y_{l}^{t+1}\right.$, $\left.x_{l}^{t}, y_{l}^{t}\right)>1$ indicates an improvement in total productivity, $M\left(x_{l}^{t+1}, y_{l}^{t+1}, x_{l}^{t}, y_{l}^{t}\right)<1$ indicates a decline, and $M\left(x_{l}^{t+1}, y_{l}^{t+1}\right.$, $\left.x_{l}^{t}, y_{l}^{t}\right)=1$ shows an unchanged productivity growth, see Caves et al. [2], and Chen [7].

\section{Main Subject}

In performance assessment inaccurate inputs would lead to biased results of efficiency. Malmquist Productivity Index is used for computing the progress and regress of entities in successive periods. It is of great importance to pay attention when Malmquist Productivity Index is being calculated for DMUs with similar performances in time $t$ and time $t+1$. Thus, a question is brought forth for discussion: would it be fair enough to merely consider efficiency variations and technological variations? Of course not. The fact is that an specific value of money in time $t$ is not equal to that value in time $t+1$, that is, $(10 \$)_{t} \neq(10 \$)_{t+1}$. Thus if technological variations and efficiency variations in time $t$ and time $t+1$ have the same performances, then, the interest rate needs to be considered in time $t+1$.

For instance consider a bank with a large financial capital in a year which has a performance lower than the interest rate in the country; it would definitely have regressed even if it have a high efficiency and positive technological variations. In this case the corresponding Malmquist Productivity Index is greater than one.

Here "single payment compound" is utilized for calculating the time value of money in two successive years. If one has $A \$$ in time $f$, corresponding value will be $A \times(1+e)^{n}$ in time $l$ where $n=l-f$ and $e$ is the interest rate in time $f$ to $l$. If $n>0$ then $A_{l} \times(1+e)^{n}=A_{f}$ and if $n<0$ then $A_{l}=A_{f} \times(1+e)^{n}$ which means that $A_{l} \times\left(1 /(1+e)^{-n}\right)=$ $A_{f}$. It makes no difference to multiply $(1+e)^{n}$ to $A_{f}$ or divide $A_{l}$ by $(1+e)^{n}$. This means those DMUs have inputs and (or) outputs influenced by time value of money should be compared on equal terms with one an other. Thus it is necessary to make these changes first and then consider the observations and compare them to the efficient frontiers. As said before in order to make these values equal it is possible to make the changes in either side of the equation. Consider $f=t$ and $l=t+1$; in this case $n=t+1-t$; thus the vale of money will be $A \times(1+e)$ in time $t+1$. As in Malmquist Productivity Index times $t$ and $t+1$ are compared with each other thus always $n=1$.

For clarity consider the following example. If one has $12 \$$ in time $t$ and $14 \$$ in time $t+1$, while all the factors, specially time value of money, are the same in these two time periods, thus progress had happed. But, if the value of $12 \$$ in time $t$ is equal to the value of $15 \$$ in time $t+1$, therefore a regress had happened. Thus, it is necessary to consider time value of money for those factors which is impressible while evaluating the progress or the regress of units.

It should be noted that if productivity is calculated in successive months the interest rate has been computed on basis of months.

This procedure will be performed for those factors on which time value of money is impressive.

Therefore, consider a situation in time $t$ in which from the $x$ units of inputs, with the interest value of $e, y$ units of outputs have been produced. In this situation, certainly, in time $t+1$ with the interest value of $e$ the inputs $(x)$ and the outputs $(y)$ are not the same as those of in time $t$. Thus, considering the time value of money for those factors on which it leaves impression, the results may be different to those acquired without regarding the time value of money. As a result, at first, the interest rate of money is expected to be accounted for them, and efficiency variations and technological variations 
should be calculated. For those factors on which interest value is not impressive, such as number of personals and equipment, there is no need to be dealt with like this, and they should be treated similar to the precedent.

Consider the previously-mentioned discussion with the time value of money is being incorporated into the analysis, the following four LPs will be presented for assessing Modified Malmquist Productivity Index.

Under constant returns to scale, the LP for $D^{t}\left(x_{l}^{t}, y_{l}^{t}\right)$, with $m$ inputs and $s$ outputs, is as follows:

$$
\begin{aligned}
\bar{D}^{t}\left(x_{l}^{t}, y_{l}^{t}\right)=\min & \theta \\
\text { s.t. } & \sum_{j=1}^{n} \lambda_{j} x_{i j}^{t} \leq \theta x_{i l}^{t}, \quad i=1, \ldots, m, \\
& \sum_{j=1}^{n} \lambda_{j} y_{r j}^{t} \geq y_{r l}^{t}, \quad r=1, \ldots, s, \\
& \lambda_{j} \geq 0, \quad j=1, \ldots, n .
\end{aligned}
$$

Similarly, the other three LP problems become

$$
\begin{aligned}
\bar{D}^{t+1}\left(x_{l}^{t}, y_{l}^{t}\right)=\min & \theta \\
\text { s.t. } \quad & \sum_{j=1}^{n} \lambda_{j} x_{i j}^{t+1} \leq \theta x_{i l}^{t}, \quad i \in I_{1}, \\
& \sum_{j=1}^{n} \lambda_{j} y_{r j}^{t+1} \geq y_{r l}^{t}, \quad r \in R_{1}, \\
& \sum_{j=1}^{n} \lambda_{j} x_{i j}^{t+1} \leq \theta(1+e)^{1} x_{i l}^{t}, \quad i \in I_{2}, \\
& \sum_{j=1}^{n} \lambda_{j} y_{r j}^{t+1} \geq(1+e)^{1} y_{r l}^{t}, \quad r \in R_{2}, \\
& \lambda_{j} \geq 0, \quad j=1, \ldots, n,
\end{aligned}
$$

where $I_{1}$ and $R_{1}$ show the subsets of inputs and outputs, respectively for which time value of money the nonimpressible and $I_{2}$ and $R_{2}$ shows the subsets of inputs and outputs, respectively, for which is the time value of money is influential. It also should be mentioned that $I=\{1, \ldots, m\}, R=$ $\{1, \ldots, s\}$ and $I=I_{1} \cup I_{2}, R=R_{1} \cup R_{2}$

$$
\begin{aligned}
\bar{D}^{t+1}\left(x_{l}^{t+1}, y_{l}^{t+1}\right)=\min & \theta \\
\text { s.t. } & \sum_{j=1}^{n} \lambda_{j} x_{i j}^{t+1} \leq \theta x_{i l}^{t+1}, \quad i=1, \ldots, m, \\
& \sum_{j=1}^{n} \lambda_{j} y_{r j}^{t+1} \geq y_{r l o}^{t+1}, \quad r=1, \ldots, s, \\
& \lambda_{j} \geq 0, \quad j=1, \ldots, n,
\end{aligned}
$$

$$
\begin{aligned}
\bar{D}^{t}\left(x_{l}^{t+1}, y_{l}^{t+1}\right)=\min & \theta \\
\text { s.t. } \quad & \sum_{j=1}^{n} \lambda_{j} x_{i j}^{t} \leq \theta x_{i l}^{t+1}, \quad i \in I_{1}, \\
& \sum_{j=1}^{n} \lambda_{j} y_{r j}^{t} \geq y_{r l}^{t+1}, \quad r \in R_{1}, \\
& \sum_{j=1}^{n} \lambda_{j}(1+e)^{1} x_{i j}^{t} \leq \theta x_{i l}^{t+1}, \quad i \in I_{2}, \\
& \sum_{j=1}^{n} \lambda_{j}(1+e)^{1} y_{r j}^{t} \geq y_{r l}^{t+1}, \quad r \in R_{2}, \\
& \lambda_{j} \geq 0, \quad j=1, \ldots, n .
\end{aligned}
$$

In model (7) subsets of inputs and outputs are the same as what has been discussed previously.

It is noteworthy of attention that in models (6) and (8) time value of money is not included. Time value of money does not influence the procedure since two similar periods are being compared with each other and since time value of money is fixed in a period. Moreover, according to the aforesaid formula $(1+e)^{n}$, when $n$ is equal to zero, one is multiplied to the input and output parameters. But, in models (7) and (9), which are considered in various periods, the time value of money, for the indexes under the influence of it, is calculated by "single payment compound" factor. The Modified Malmquist Productivity Index is calculated like the preceding classic analysis through the following formula:

$$
\begin{aligned}
& \bar{M}\left(x_{i}^{t+1}, y_{i}^{t+1}, x_{i}^{t}, y_{i}^{t}\right) \\
& =\frac{\bar{D}^{t+1}\left(x_{i}^{t+1}, y_{i}^{t+1}\right)}{\bar{D}^{t}\left(x_{i}^{t}, y_{i}^{t}\right)}\left[\frac{\bar{D}^{t}\left(x_{i}^{t+1}, y_{i}^{t+1}\right) \bar{D}^{t}\left(x_{i}^{t}, y_{i}^{t}\right)}{\bar{D}^{t+1}\left(x_{i}^{t+1}, y_{i}^{t+1}\right) \bar{D}^{t+1}\left(x_{i}^{t}, y_{i}^{t}\right)}\right]^{1 / 2} .
\end{aligned}
$$

Considering the aforesaid discussion, in regards of (10) it can be concluded that $\bar{M}\left(x_{i}^{t+1}, y_{i}^{t+1}, x_{i}^{t}, y_{i}^{t}\right)>1$ indicates productivity gain, $\bar{M}\left(x_{i}^{t+1}, y_{i}^{t+1}, x_{i}^{t}, y_{i}^{t}\right)<1$ indicates productivity loss, and $\bar{M}\left(x_{i}^{t+1}, y_{i}^{t+1}, x_{i}^{t}, y_{i}^{t}\right)=1$ means no change in productivity from time $t$ to time $t+1$.

\section{Application}

In early work in this field, productivity change was explained in terms of technical change, and efficiency change but in this paper according to the mentioned discussion it has been convinced that present time value of money plays an influential role in showing the progress or regress of an entity; thus this factor should also be accounted for.

Here an application of the methodology to the Iranian banks in the period of 2006 to 2009 has been examined. Employing the Malmquist Productivity Index which is calculated based on data envelopment analysis' models, 
TABle 1: Description.

\begin{tabular}{lcc}
\hline Index & Status \\
\hline & Input & \\
\hline Asses quality $\left(I_{1}\right)$ & & Nonimpressible \\
Rate of deposit growth $\left(I_{2}\right)$ & Nonimpressible \\
Total possessing $\left(I_{3}\right)$ & Impressible \\
Personal costs $\left(I_{4}\right)$ & Impressible \\
Interest payment $\left(I_{5}\right)$ & Output & Impressible \\
\hline & & Nonimpressible \\
Profit marginal $\left(\mathrm{O}_{1}\right)$ & Nonimpressible \\
Rate of revenue growth $\left(\mathrm{O}_{2}\right)$ & Impressible \\
Received commission $\left(\mathrm{O}_{3}\right)$ & & Impressible \\
Share-holders equity $\left(\mathrm{O}_{4}\right)$ & Impressible \\
Acquired interest $\left(\mathrm{O}_{5}\right)$ & Impressible \\
Total revenue $\left(\mathrm{O}_{6}\right)$ &
\end{tabular}

productivity measure can be computed. The incorporation of present time value of money is also calculated within the framework of data envelopment analysis as showed in previous section.

Over the last years, the standard structural analysis that has taken place in the productivity measurement has been developed in terms of technical change and efficiency change, but the actuality is that present time value of money should also be incorporated into the analysis. In Table 1 we give a brief explanation about variables. The input-output indexes are listed in Tables 2-5. Also, it is specified as to whether they are under the influence of the time value of money. As you can see, for some indexes like "Asses quality" and "rate of deposit growth" time value of money is not influential and they are indicated as "nonimpressible" and for some other as "total possessing" and "personal costs", it is observable and it should be considered into the analysis. These indexes are indicated as "impressible."

According to the presented models and aforesaid discussions, the present time value of money is also incorporated into the analysis within the framework of data envelopment analysis. As shown in previous section, Modified Malmquist Productivity Index has been calculated and the results of these two analysis are gathered in Tables 6-10.

As it was shown in the following tables MMPI model yields different results in comparison to those of MPI. On regards of the interest rate in 2006-2007, 2007-2008, and 2008-2009 it can be found out that on basis of the first wrong picture which shows a progress in some of the banks, all of them in the first period of analysis have made regress. That means that those banks have shown lower performance in contrast to that of classic model. Thus, one of the influential factors which should be incorporated while progress and regress of organizations are being analyzed is to calculate the interest rate and time value of money. It is worthy of attention that in developing countries interest rate has a great amount, and its effect on economics transactions has a significant role. In this application the interest rates of 2006-2007, 2007-2008, and $2008-2009$ are $16 \%, 18.4 \%$, and $12.5 \%$, respectively.

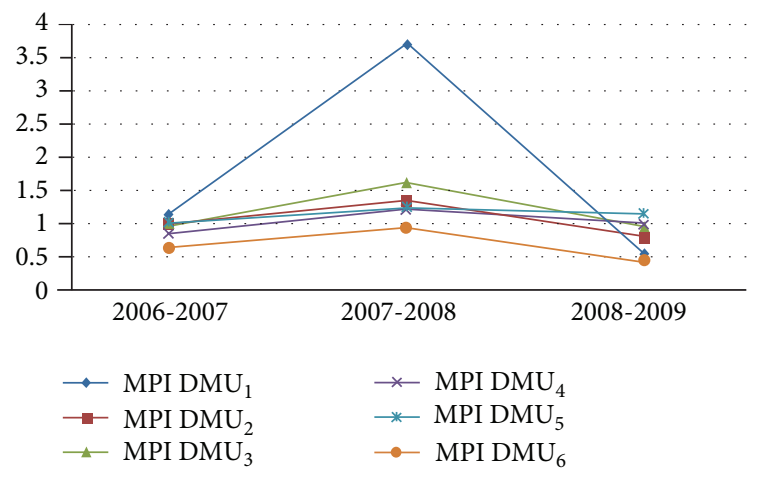

Figure 1: Malmquist Productivity Index.

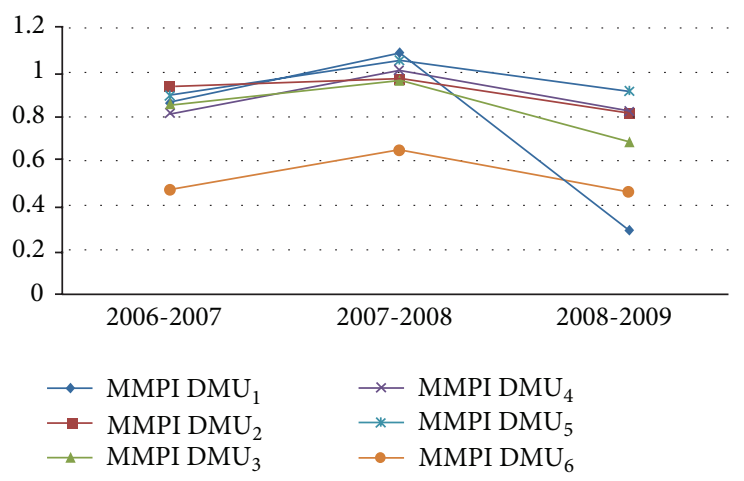

FIGURe 2: Modified Malmquist Productivity Index.

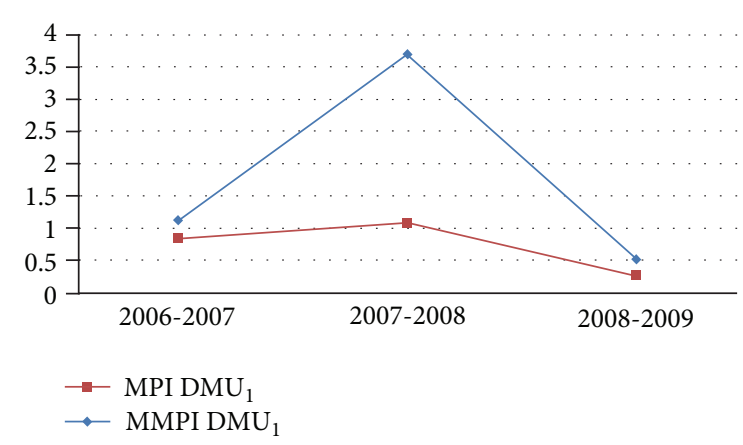

FIGURE 3: Malmquist changes for $\mathrm{DMU}_{1}$.

In the second period due to the reduction of interest value and corresponding variations of time value of money, the performance of banks has been improved somehow. But, while the acquired results have being compared to those obtained from classic model, which shows five banks has made progress, in modified analysis only three banks have progressed.

Considering the acquired results from modified analysis in the third period it has been revealed that all banks have regressed. By inclusion of the interest rate in modified model for those banks which are under evaluation, a warning bell rings which shows the weak performance of Iranian banks in successive periods while this factor has been considered. 
TABLE 2: Inputs and outputs (2006).

\begin{tabular}{lccccccccccc}
\hline DMUs & $I_{1}$ & $I_{2}$ & $I_{3}$ & $I_{4}$ & $I_{5}$ & $O_{1}$ & $O_{2}$ & $O_{3}$ & $O_{4}$ & $O_{5}$ \\
\hline 1 & 0.824 & 0.350 & 90906777 & 1546117 & 3733535 & 0.021 & 0.359 & 474259 & 2314028 & 5456846 & 6242343 \\
2 & 0.916 & 0.381 & 42765690 & 761666 & 1531782 & 0.039 & 0.381 & 147729 & 1227237 & 2986501 & 3281831 \\
3 & 0.848 & 0.297 & 61415068 & 1012123 & 2713555 & 0.037 & 0.364 & 172220 & 2192410 & 4774258 & 5165554 \\
4 & 0.914 & 0.280 & 31843148 & 562000 & 1322229 & 0.027 & 0.417 & 136994 & 1116026 & 2109188 & 2380064 \\
5 & 0.857 & 0.419 & 39809905 & 612876 & 1580745 & 0.028 & 0.397 & 188265 & 1323499 & 2583767 & 2862649 \\
6 & 0.882 & 0.360 & 9190113 & 209150 & 322760 & 0.056 & 0.854 & 42873 & 650130 & 772256 & 860719 \\
\hline
\end{tabular}

TABLE 3: Inputs and outputs (2007).

\begin{tabular}{lccccccccccc}
\hline DMUs & $I_{1}$ & $I_{2}$ & $I_{3}$ & $I_{4}$ & $I_{5}$ & $O_{1}$ & $O_{2}$ & $O_{3}$ & $O_{4}$ & $O_{5}$ & $O_{6}$ \\
\hline 1 & 0.845 & 0.259 & 106959115 & 2045491 & 4746010 & 0.016 & 0.272 & 460303 & 2292258 & 6279449 & 7943232 \\
2 & 0.912 & 0.240 & 52281855 & 988163 & 2202181 & 0.029 & 0.227 & 215136 & 1125702 & 3568242 & 4026108 \\
3 & 0.866 & 0.240 & 66852215 & 1267093 & 3450791 & 0.027 & 0.106 & 178679 & 1962481 & 5209039 & 5711620 \\
4 & 0.915 & 0.273 & 38858011 & 719412 & 1737239 & 0.030 & 0.323 & 181317 & 1234487 & 2815229 & 3148523 \\
5 & 0.956 & 0.361 & 66933174 & 987139 & 2039642 & 0.027 & 0.328 & 222179 & 2262840 & 3456352 & 3802313 \\
6 & 0.887 & 0.735 & 13969634 & 317444 & 329968 & 0.060 & 0.376 & 76364 & 998289 & 1025285 & 1184574 \\
\hline
\end{tabular}

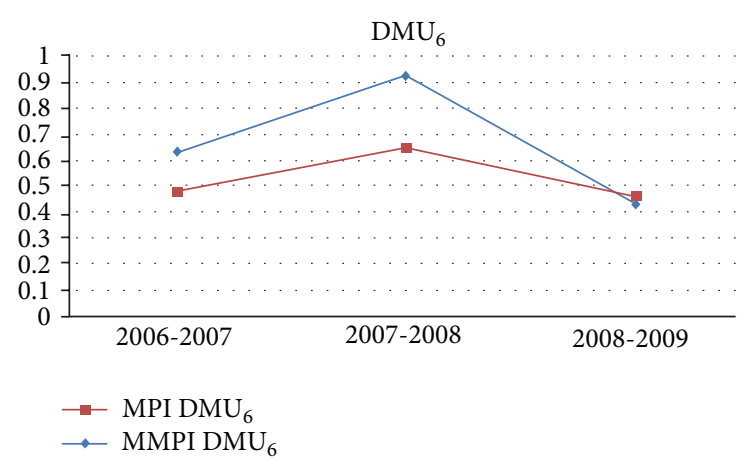

FIGURE 4: Malmquist changes for $\mathrm{DMU}_{6}$.

While the increasing interest rate is being incorporated, in the event that the technology has not changed, banks encountered a regress, and this difficulty should be prevented and an immediate action must be taken.

In the following, performance of each bank is being compared to that of itself in different periods. It can also be discussed that if the performance in 2006 is being compared to that of 2009 in the corresponding model $n$ should be replaced with 3 ; that means a computation of three periods for interest rate.

As it can be seen in the following figures, variations in classic and Modified Malmquist Productivity Indexes have major differences. In classic analysis, except $\mathrm{DMU}_{1}$, other DMUs have similar variations, but in that of modified one variations have various procedures. Variations in classic Malmquist Productivity Index are described in Figure 1.

Also, variations in Modified Malmquist Productivity Index are depicted in Figure 2. In the following, variations in classic and Modified Malmquist Productivity Indexes will be specifically discussed for two DMUs $\left(\mathrm{DMU}_{1}\right.$ and $\left.\mathrm{DMU}_{6}\right)$.
For the first bank $\left(\mathrm{DMU}_{1}\right)$, variations of Malmquist Productivity Index is as what has been seen in Figure 3. The progress that $\mathrm{DMU}_{1}$, in classic models, has made is totally different from that of the modified analysis, and the variance of variations in the modified approach is more rationale. That means, all of the under-assessment banks in years of analysis do not have significant technological variations. Thus, the corresponding Malmquist Index has a more stable procedure. This fact in modified analysis is considerable. Now, consider Figure 4 which shows variations in classic and modified approaches for $\mathrm{DMU}_{6}$. Modified Malmquist Productivity Index in the third period has revealed a lower regress in comparison to that of second period. Whereas, in classic analysis it witnessed an intense decrease while being compared to the second period. As a consequence of considering the present time value of money according to the aforesaid discussion it has been shown that regarding the modified analysis has led to different results while Malmquist Productivity Index is being calculated.

\section{Conclusion}

Classic Malmquist Productivity Index, in different periods, without considering the present value of money, shows regress and progress of a DMU while considering efficiency and technology variations. This shortcoming would yield biased results which can affect the correct interpretation since a currency in last year in not equal to the that of this. Noted that performance assessment with inaccurate inputs would lead to biased results of efficiency. This shortcoming would affect Malmquist Productivity Index which is used to compute the progress and regress of entities in successive periods. Thus it is obvious that it would not be fair enough to merely consider efficiency and technological variations. The index developed here has been defined in terms of Modified Malmquist Productivity Index (MMPI) model, which can calculate progress and regress by using the factor of present 
TABLE 4: Inputs and outputs (2008).

\begin{tabular}{lccccccccccc}
\hline DMUs & $I_{1}$ & $I_{2}$ & $I_{3}$ & $I_{4}$ & $I_{5}$ & $O_{1}$ & $O_{2}$ & $O_{3}$ & $O_{4}$ & $O_{5}$ & $O_{6}$ \\
\hline 1 & 0.838 & 0.268 & 16281551 & 2622188 & 6131088 & 0.025 & 0.494 & 716748 & 8012504 & 9522348 & 11869855 \\
2 & 0.922 & 0.498 & 94278569 & 1240252 & 3380231 & 0.030 & 0.617 & 330604 & 3972909 & 5549420 & 6509109 \\
3 & 0.787 & 0.406 & 128550383 & 1903395 & 4582403 & 0.041 & 0.728 & 595662 & 5648607 & 8656018 & 9870337 \\
4 & 0.940 & 0.327 & 62867728 & 990467 & 2241437 & 0.034 & 0.461 & 328427 & 2365168 & 3985100 & 4600389 \\
5 & 0.960 & 0.326 & 88157665 & 1258469 & 2891489 & 0.026 & 0.464 & 384005 & 2267367 & 4916408 & 5567726 \\
6 & 0.790 & 0.464 & 20262710 & 491521 & 732181 & 0.056 & 0.606 & 110347 & 1088278 & 1691760 & 1902707 \\
\hline
\end{tabular}

TABLE 5: Inputs and outputs (2009).

\begin{tabular}{lccccccccccc}
\hline DMUs & $I_{1}$ & $I_{2}$ & $I_{3}$ & $I_{4}$ & $I_{5}$ & $O_{1}$ & $O_{2}$ & $O_{3}$ & $O_{4}$ & $O_{5}$ & $O_{6}$ \\
\hline 1 & 0.872 & 0.243 & 215200038 & 3624698 & 8301843 & 0.014 & 0.319 & 2189673 & 6770928 & 11133284 & 15660622 \\
2 & 0.967 & 0.388 & 146756030 & 1688724 & 4416677 & 0.037 & 0.307 & 470243 & 4327269 & 7275909 & 8507807 \\
3 & 0.823 & 0.188 & 149243454 & 2223659 & 5216403 & 0.035 & 0.166 & 756999 & 5142175 & 10133005 & 11504037 \\
4 & 0.933 & 0.226 & 83332310 & 1124923 & 3350167 & 0.026 & 0.416 & 501502 & 2639362 & 5286830 & 6512891 \\
5 & 0.971 & 0.245 & 114430158 & 1516034 & 3951486 & 0.024 & 0.327 & 701409 & 2940119 & 6342139 & 7387085 \\
6 & 0.853 & 0.385 & 27618519 & 651419 & 1256218 & 0.031 & 0.221 & 154685 & 1136311 & 2005444 & 2323583 \\
\hline
\end{tabular}

TABle 6: Malmquist index comparison of 2007 to 2006.

\begin{tabular}{lccccc}
\hline DMUs & MPI & MPI status & MMPI & MMPI status & Differences \\
\hline 1 & 1.134 & Progress & 0.864 & Regress & Changed \\
2 & 0.988 & Regress & 0.935 & Regress & Equable \\
3 & 0.997 & Regress & 0.855 & Regress & Equable \\
4 & 0.844 & Regress & 0.816 & Regress & Equable \\
5 & 1.025 & Progress & 0.897 & Regress & Changed \\
6 & 0.634 & Regress & 0.480 & Regress & Equable \\
\hline
\end{tabular}

TABLE 7: Malmquist index comparison of 2008 to 2007.

\begin{tabular}{lccccc}
\hline DMUs & MPI & MPI status & MMPI & MPI status & Differences \\
\hline 1 & 3.704 & Progress & 1.090 & Progress & Equable \\
2 & 1.338 & Progress & 0.967 & Regress & Changed \\
3 & 1.609 & Progress & 0.963 & Regress & Changed \\
4 & 1.199 & Progress & 1.010 & Progress & Equable \\
5 & 1.243 & Progress & 1.056 & Progress & Equable \\
6 & 0.927 & Regress & 0.649 & Regress & Equable \\
\hline
\end{tabular}

TABLE 8: Malmquist index comparison in 2009 to 2008.

\begin{tabular}{lccccc}
\hline DMUs & MPI & MPI Status & MMPI & MMPI Status & Differences \\
\hline 1 & 0.530 & Regress & 0.289 & Regress & Equable \\
2 & 0.804 & Regress & 0.816 & Regress & Equable \\
3 & 0.944 & Regress & 0.687 & Regress & Equable \\
4 & 0.996 & Regress & 0.828 & Regress & Equable \\
5 & 1.150 & Progress & 0.917 & Regress & Changed \\
6 & 0.430 & Regress & 0.461 & Regress & Equable \\
\hline
\end{tabular}

time value of money. It should be noted that the incorporation of present time value of money is also calculated within the framework of data envelopment analysis. In the case study presented here the major concentration is showing the true progress and regress of bank branches. Moreover, those
TABle 9: Malmquist Productivity Index.

\begin{tabular}{lccc}
\hline DMUs & $\begin{array}{c}\text { MPI } \\
(2006-2007)\end{array}$ & $\begin{array}{c}\text { MPI } \\
(2007-2008)\end{array}$ & $\begin{array}{c}\text { MPI } \\
(2008-2009)\end{array}$ \\
\hline 1 & 1.134 & 3.704 & 0.530 \\
2 & 0.988 & 1.338 & 0.804 \\
3 & 0.997 & 1.609 & 0.944 \\
4 & 0.844 & 1.199 & 0.996 \\
5 & 1.025 & 1.243 & 1.150 \\
6 & 0.634 & 0.927 & 0.430 \\
\hline
\end{tabular}

TABle 10: Modified Malmquist Productivity Index.

\begin{tabular}{lccc}
\hline DMUs & $\begin{array}{c}\text { MMPI } \\
(2006-2007)\end{array}$ & $\begin{array}{c}\text { MMPI } \\
(2007-2008)\end{array}$ & $\begin{array}{c}\text { MMPI } \\
(2008-2009)\end{array}$ \\
\hline 1 & 0.864 & 1.090 & 0.289 \\
2 & 0.935 & 0.967 & 0.816 \\
3 & 0.855 & 0.963 & 0.687 \\
4 & 0.816 & 1.010 & 0.828 \\
5 & 0.897 & 1.056 & 0.917 \\
6 & 0.480 & 0.649 & 0.461 \\
\hline
\end{tabular}

factors on which the time value of money is impressible are mainly financial ones that are under the influence of the interest rate. Thus while considering Time Value of Money, further investigations of other concepts relevant to DEA can also be considered from this point of view.

\section{References}

[1] S. Malmquist, "Index numbers and indifference surfaces," Trabajos de Estadistica, vol. 4, no. 2, pp. 209-242, 1953.

[2] D. W. Caves, L. R. Christensen, and W. E. Diewert, "The economic theory of index numbers and the measurement of input, output and productivity," Econometrica, vol. 50, no. 6, pp. 1393-1414, 1982. 
[3] R. Färe, S. Grosskopf, M. Norris, and Z. Zhang, "Productivity growth, technical progress, and efficiency change in industrialized countries," The American Economic Review, vol. 84, no. 1, pp. 66-83, 1994.

[4] N. Maniadakis and E. Thanassoulis, "A cost Malmquist productivity index," European Journal of Operational Research, vol. 154, no. 2, pp. 396-409, 2004.

[5] E. Grifell-Tatjé and C. A. K. Lovell, "A DEA-based analysis of productivity change and intertemporal managerial performance," Annals of Operations Research, vol. 73, pp. 177-189, 1997.

[6] E. Grifell-Tatjé, C. A. K. Lovell, and J. T. Pastor, "A QuasiMalmquist productivity index," Journal of Productivity Analysis, vol. 10, no. 1, pp. 7-20, 1998.

[7] Y. Chen, "A non-radial Malmquist productivity index with an illustrative application to Chinese major industries," International Journal of Production Economics, vol. 83, no. 1, pp. 27-35, 2003.

[8] H. J. Fuentes, E. Grifell-Tatjé, and S. Perelman, "A parametric distance function approach for Malmquist productivity index estimation," Journal of Productivity Analysis, vol. 15, no. 2, pp. 79-94, 2001.

[9] L. Orea, "Parametric decomposition of a generalized Malmquist productivity index," Journal of Productivity Analysis, vol. 18, no. 1, pp. 5-22, 2002.

[10] T. T. Lin, C.-C. Lee, and T.-F. Chiu, "Application of DEA in analyzing a bank's operating performance," Expert Systems with Applications, vol. 36, no. 5, pp. 8883-8891, 2009.

[11] T.-C. Wang and Y.-L. Lin, "Applying the consistent fuzzy preference relations to select merger strategy for commercial banks in new financial environments," Expert Systems with Applications, vol. 36, no. 3, pp. 7019-7026, 2009.

[12] H.-Y. Wu, G.-H. Tzeng, and Y.-H. Chen, "A fuzzy MCDM approach for evaluating banking performance based on Balanced Scorecard," Expert Systems with Applications, vol. 36, no. 6, pp. 10135-10147, 2009.

[13] G. S. Ng, C. Quek, and H. Jiang, "FCMAC-EWS: a bank failure early warning system based on a novel localized pattern learning and semantically associative fuzzy neural network," Expert Systems with Applications, vol. 34, no. 2, pp. 989-1003, 2008. 


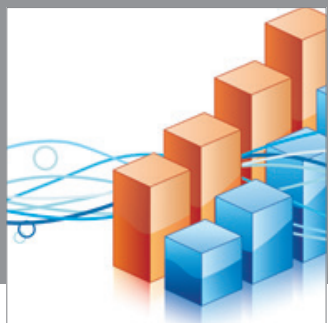

Advances in

Operations Research

mansans

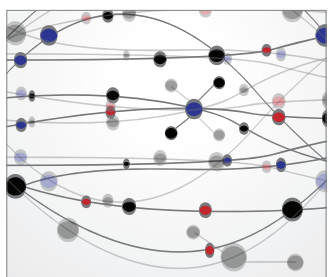

The Scientific World Journal
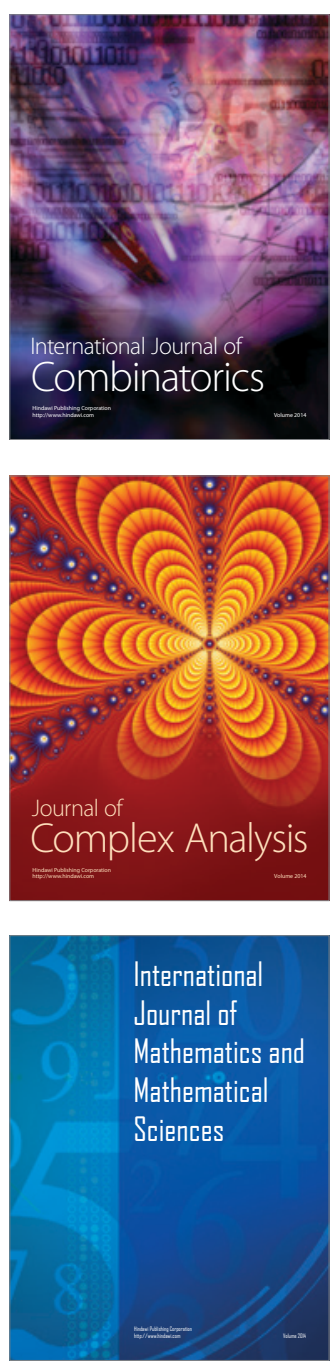
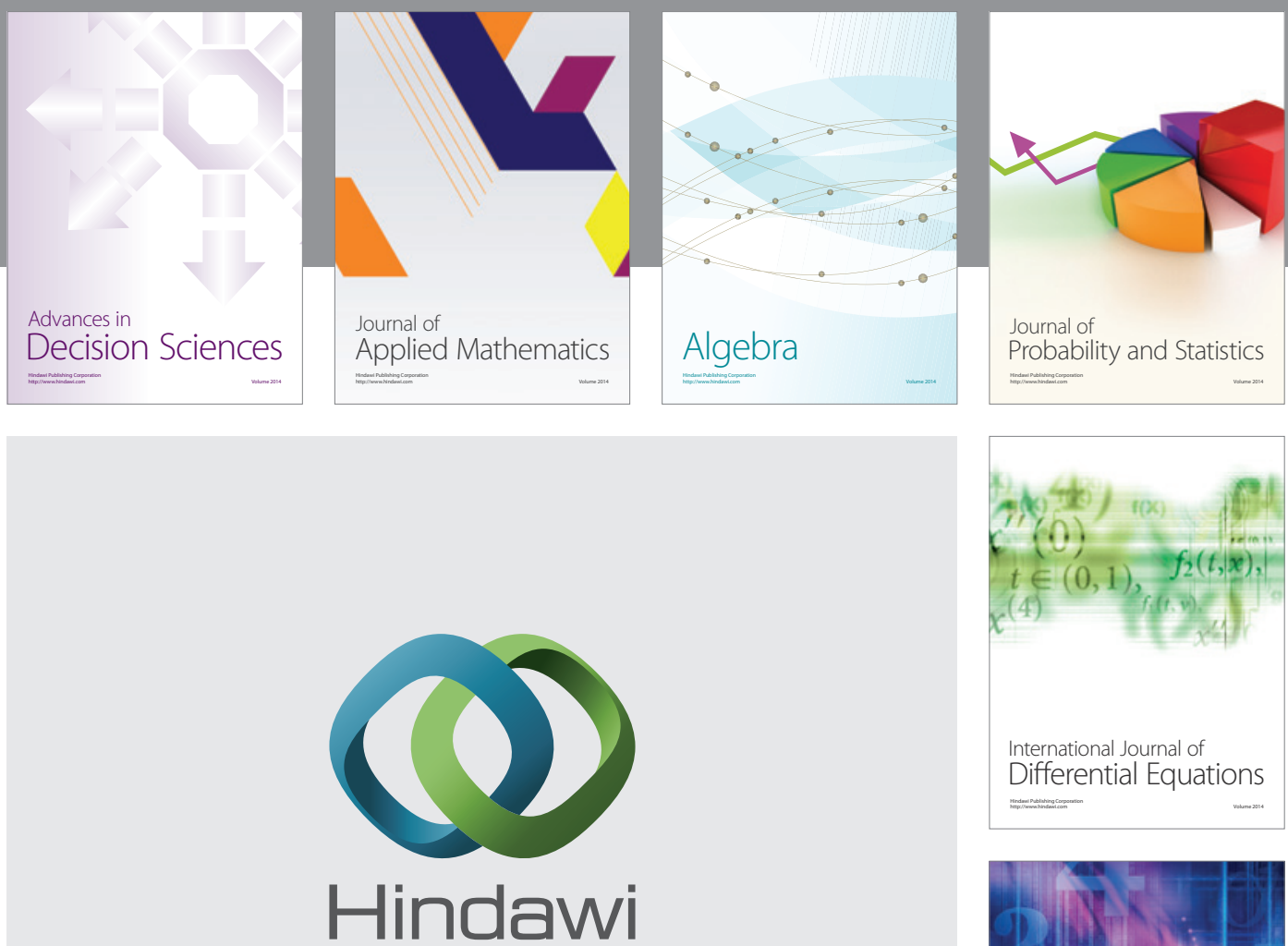

Submit your manuscripts at http://www.hindawi.com
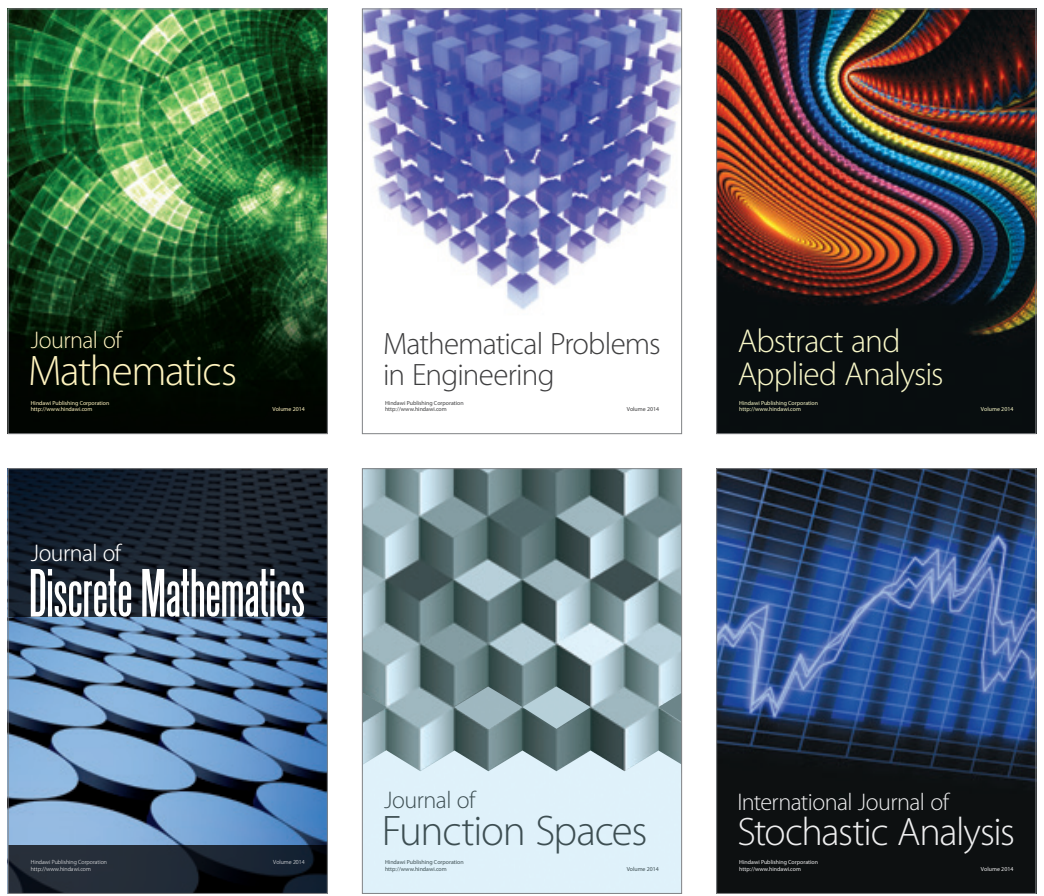

Journal of

Function Spaces

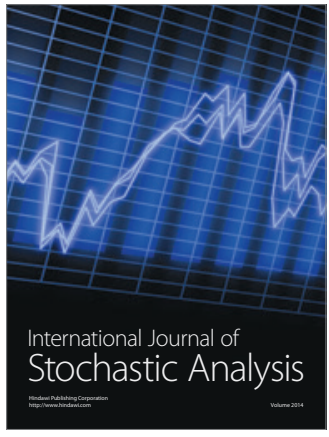

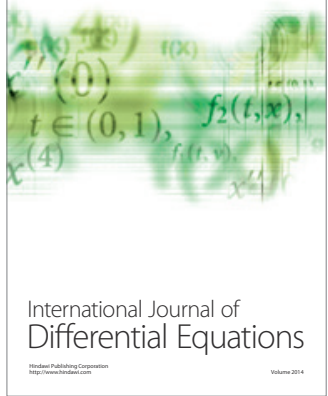
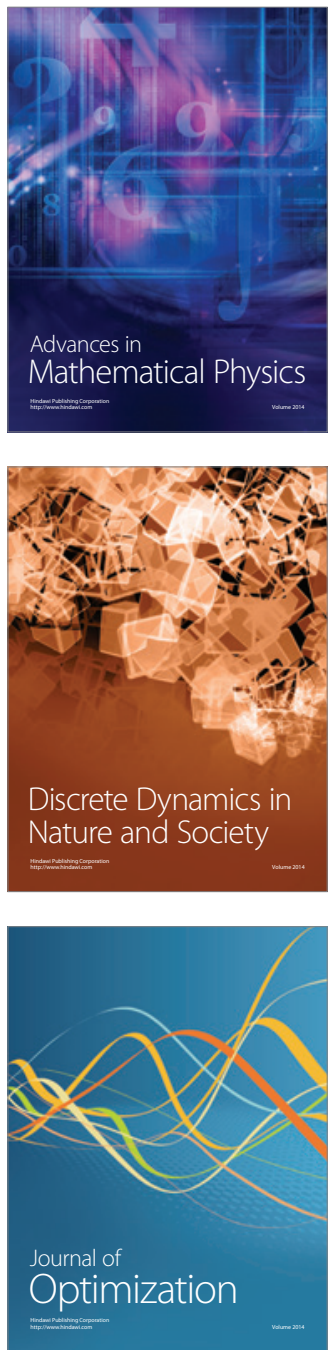